Article

\title{
Remote Sensing of Particle Cross-Sectional Area in the Bohai Sea and Yellow Sea: Algorithm Development and Application Implications
}

\author{
Shengqiang Wang ${ }^{1,2}$, Yu Huan ${ }^{1}$, Zhongfeng Qiu ${ }^{1,2, *}$, Deyong Sun ${ }^{1,2}$, Hailong Zhang ${ }^{1}$, \\ Lufei Zheng ${ }^{1}$ and Cong Xiao ${ }^{1}$ \\ 1 School of Marine Sciences, Nanjing University of Information Science \& Technology (NUIST), \\ Nanjing 210044, Jiangsu, China; shengqiang.wang@nuist.edu.cn (S.W.); huanyu0624@foxmail.com (Y.H.); \\ sundeyong1984@163.com (D.S.); zhanghailong.1205@163.com (H.Z.); lufei.z@foxmail.com (L.Z.); \\ rafaxiaocong@163.com (C.X.) \\ 2 Jiangsu Research Center for Ocean Survey Technology, NUIST, Nanjing 210044, Jiangsu, China \\ * Correspondence: zhongfeng.qiu@nuist.edu.cn; Tel.: +86-25-5869-5692
}

Academic Editors: Claudia Giardino, Linhai Li, Yunlin Zhang, Xiaofeng Li and Prasad S. Thenkabail Received: 26 July 2016; Accepted: 8 October 2016; Published: 22 October 2016

\begin{abstract}
Suspended particles in waters play an important role in determination of optical properties and ocean color remote sensing. To link suspended particles to their optical properties and thereby remote sensing reflectance $\left(R_{\mathrm{rs}}(\lambda)\right)$, cross-sectional area is a key factor. Till now, there is still a lack of methodologies for derivation of the particle cross-sectional area concentration (AC) from satellite measurements, which consequently limits potential applications of AC. In this study, we investigated the relationship between $\mathrm{AC}$ and $R_{\mathrm{rs}}(\lambda)$ based on field measurements in the Bohai Sea (BS) and Yellow Sea (YS). Our analysis confirmed the strong dependence of $R_{\mathrm{rs}}(\lambda)$ on AC and that such dependence is stronger than on mass concentration. Subsequently, a remote sensing algorithm that uses the slope of $R_{\mathrm{rs}}(\lambda)$ between 490 and $555 \mathrm{~nm}$ was developed for retrieval of AC from satellite measurements of the Geostationary Ocean Color Imager (GOCI). In situ evaluations show that the algorithm displays good performance for deriving AC and is robust to uncertainties in $R_{\mathrm{rs}}(\lambda)$. When the algorithm was applied to satellite data, it performed well, with a coefficient of determination of 0.700 , a root mean squared error of $2.126 \mathrm{~m}^{-1}$ and a mean absolute percentage error of $40.7 \%$, and it yielded generally reasonable spatial and temporal distributions of AC in the BS and YS. The satellite-derived AC using our algorithm may offer useful information for modeling the inherent optical properties of suspended particles, deriving the water transparency, estimating the particle composition and possibly improving particle mass concentration estimations in future.
\end{abstract}

Keywords: particle cross-sectional area; remote sensing; retrieval model; the Bohai Sea and Yellow Sea; Geostationary Ocean Color Imager (GOCI)

\section{Introduction}

Suspended particles are an important type of matter in coastal and oceanic waters because of their significant roles in marine physical and biogeochemical processes [1,2]. More specifically, sunlight entering the near surface of the sea is attenuated by suspended particles due to absorption and scattering. This process significantly impacts the depth of penetration of sunlight into the sea, which regulates marine primary production [3,4]. At the same time, certain fractions of sunlight are scattered backward by suspended particles to emerge from the sea surface. This backscattered light is the essential foundation of ocean color remote sensing for monitoring of suspended particles, water transparency, turbidity, etc., using satellite measurements [5]. Thus, knowledge of the 
properties of suspended particles related to light attenuation is fundamentally important for improved understanding of water radiative transfer, aquatic photosynthesis processes and ocean color algorithms.

Theoretically, when a photon enters the sea, the probability of the photon interacting with a particle depends on its cross-sectional area [6,7]. The optical properties (e.g., light attenuation, scattering and backscattering coefficients) are therefore directly related to the particle cross-sectional area concentration (AC) $[7,8]$. Taking the backscattering coefficient $b_{\mathrm{bp}}(\lambda)$ as an example, based on the assumption of a sphere for particle, the relationship between $b_{\mathrm{bp}}(\lambda)$ and $\mathrm{AC}$ is expressed as follows [9].

$$
b_{\mathrm{bp}}(\lambda)=Q_{\mathrm{bbe}}(\lambda) \mathrm{AC}
$$

where $Q_{\text {bbe }}(\lambda)$ indicates the backscattering efficiency. Though AC is known to be important for understanding optical properties of particles, field measurement of AC has been a technical difficulty in the past. Therefore, mass concentration of total suspended matters (TSM) which can be easily measured using filtration of water samples in the field is often used by researchers to understand optical properties $[4,6]$. However, note that there is no exact theoretical basis between TSM and optical properties. The observed relationship between TSM and optical properties is actually based on the correlation of TSM with AC, but such correlation is not stable due to additional impacts of the size distribution and density of particles [7,8].

In the past decade, field instruments such as digital cameras and laser diffraction (e.g., laser in situ scattering and transmissometry device, LISST) have gradually made it easier to measure the AC of suspended particles [10-12]. For instance, volume concentrations of suspended particles in a given size bin can be derived through inversion of the near-forward scattering measured by a LISST instrument. Based on information on the distribution of particle volume with size, the AC of suspended particles can be calculated by assuming a spherical shape and material homogeneity for the particles. Due to the available measurements of AC, increasing numbers of laboratory and field studies have been conducted in recent years to investigate the impacts of AC on the optical properties of particles under various conditions (e.g., flocculation and phytoplankton bloom) [8,9,11-15]. These studies have clearly showed that the optical properties of suspended particles strongly depend on AC, and this dependence is stronger than TSM. For instance, Hatcher et al. [11] observed that for suspension of aggregates $(>10 \mu \mathrm{m})$, although a drop in TSM was noted and caused poor correlation between $b_{\mathrm{bp}}(\lambda)$ and TSM, the linear relationship between $b_{\mathrm{bp}}(\lambda)$ and AC still performed well. In two typical shallow and semi-enclosed seas, namely, the Bohai Sea (BS) and the Yellow Sea (YS), Wang et al. [15] also found that $\mathrm{AC}$ is strongly related to both attenuation coefficient and $b_{\mathrm{bp}}(\lambda)$ (coefficient of determination $\left.R^{2}>0.90\right)$. Meanwhile, LISST measurements of volume concentrations of suspended particles in a given size also enable determining more biogeochemical information about particles, such as particle size distribution and density; and thus to better understand optical properties of particles $[9,15,16]$.

As the improvement in knowledge of controlling factors (e.g., AC, particle size distribution and density) of optical properties of particles, some studies have attempted to derive more plentiful biogeochemical properties of particles from satellite observations in addition to TSM, such as particle size distribution [17]. For AC, several studies have also examined its relationship with remote sensing reflectance $\left(R_{\mathrm{rs}}(\lambda)\right)$, and compared with that between $R_{\mathrm{rs}}(\lambda)$ and TSM $[7,8,14,18]$. For instance, during a laboratory experiment, Bale et al. [18] observed that when the size of the suspended particles varied from large to fine, $R_{\mathrm{rs}}(\lambda)$ increased 10-fold despite the constant value of TSM, while such increases in $R_{\mathrm{rs}}(\lambda)$ were strongly correlated with $\mathrm{AC}$, showing a $R^{2}$ value of 0.897 . Meanwhile, based on field observations, Mikkelsen [8] showed that reflectance spectra are highly dependent on AC rather than TSM. Similarly, using in situ measurements in shelf seas and estuaries, Bowers \& Braithwaite [7] claimed that reflectance is more closely linked to the AC of suspended mineral particles (mainly in flocculation conditions) than they are to TSM, with $R^{2}$ values of 0.82 and 0.53 with AC and TSM, respectively. At this stage, we must note that although previous studies have examined the relationship between $R_{\mathrm{rs}}(\lambda)$ with $\mathrm{AC}$, and provided clear evidence indicating a closer relationship between $R_{\mathrm{rs}}(\lambda)$ with AC than TSM. There is still a lack of methodologies for successful derivation of AC from satellite 
measurements. This gap consequently limits potential satellite applications of AC, such as modeling of the inherent optical properties of particles, detecting water turbidity, and retrieval of particle composition, among others.

In this study, we mainly focus on the development of the AC estimation model. Based on an in situ dataset composed of AC of particles derived from LISST measurements and the corresponding $R_{\mathrm{rs}}(\lambda)$ collected during three cruises in the BS and YS, we firstly investigated the relationships between $\mathrm{AC}$ and $R_{\mathrm{rs}}(\lambda)$ and evaluated the capability of several spectral indicators of $R_{\mathrm{rs}}(\lambda)$ for derivation of AC. Consequently, a remote sensing algorithm was proposed for mapping AC in the BS and YS from ocean color data, and potential satellite applications of AC were further discussed.

\section{Materials and Methods}

\subsection{Study Area and Sampling}

The data used in this study were collected during three cruises in May 2014, November 2014 and August 2015 in the BS and the YS aboard the R/V Dongfanghong 2 (Figure 1). The BS is known as a shallow (average depth of $18 \mathrm{~m}$ ) and highly productive inner sea of China [19]. A notably large amount of mineral-rich particles carried by the Yellow River flows into the BS. Additionally, in the past several decades, the BS has been strongly impacted by human activities because of the rapid proliferation of surrounding industries, agriculture, aquaculture and domestic sewage [19]. The YS is one of the largest marginal seas in the western North Pacific, with an area of $380,000 \mathrm{~km}^{2}$ and an average water depth of $44 \mathrm{~m}$. The YS is semi-enclosed by the contiguous lands of China in the west and Korea in the east and is connected with the BS through the Bohai Strait. Because of freshwater discharge from inland rivers carrying abundant nutrients and sediments and water mixing driven by winds and tides, water properties in the YS are regionally and seasonally varied over a wide dynamic range $[20,21]$. In addition, the YS is influenced by industrial pollution, agricultural runoff, and domestic sewage [21].

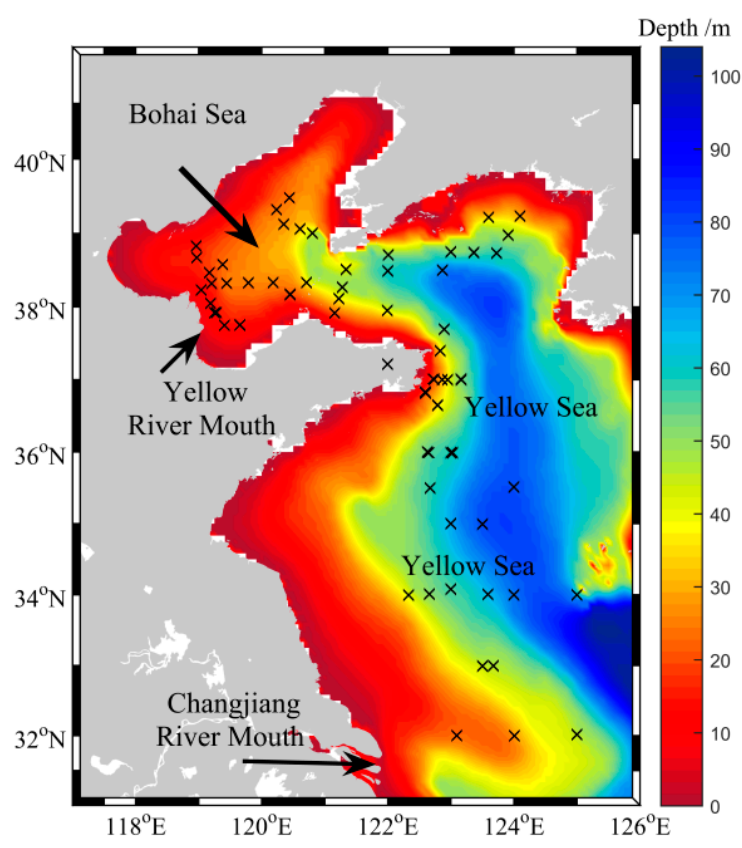

Figure 1. Locations of sampling stations in the Bohai Sea and the Yellow Sea during three cruises in 2014 and 2015. Colors indicate water depth.

At each sampling station, a profiling package was used to measure various water properties. This package includes a Sequoia Scientific LISST-100X (type C) for determining the particle size 
distribution (PSD), a Seabird SBE911P conductivity-temperature-depth (CTD) profiler for measuring the hydrological characteristics of the water column, and other optical instruments (i.e., a WET labs AC-S and a HOBI Labs Hydroscat-6) used to determine the inherent optical properties of water. The profiling package was immersed in surface waters for several minutes to equilibrate the sensor temperature and the seawater temperature, and was subsequently slowly $\left(0.2 \mathrm{~m} \cdot \mathrm{s}^{-1}\right)$ lowered from the surface to 2-3 $\mathrm{m}$ above the bottom to measure a vertical profile. We used only downcast measurements for data analysis to avoid perturbations of the package on the water column. At the daytime stations, a Satlantic Hyper-Profiler II radiometer was used to derive $R_{\mathrm{rs}}(\lambda)$. Similarly, this instrument was also stabilized at the surface water for several minutes to reduce the influence of temperature differences between sensor and water. This process also allowed the instrument to drift further away from the ship to avoid the ship's shadow. Using a hand-controlled cable, we lowered the instrument from the surface in vertical free-fall mode until it reached the euphotic layer, which is defined as the depth with $1 \%$ surface photosynthetically active radiation [22]. The downcast measurements were used in determining of $R_{\mathrm{rs}}(\lambda)$. In addition, surface water samples for measurement of TSM concentrations were simultaneously collected using 12-liter Niskin bottles mounted on a CTD/rosette system. In total, 86 surface samples with good quality were obtained that incorporated all measurements from the profiling package, Hyper-Profiler II and TSM concentrations.

\subsection{In Situ Data Measurements}

The cross-sectional area concentration AC values were calculated from field measurements of the volume scattering function using a LISST-100X Type-C particle size analyzer (Sequioa Scientific Inc., Bellevue, WA, USA). In brief, this instrument records the light scattering of particles at a wavelength of $670 \mathrm{~nm}$ at 32 logarithmically spaced scattering angles in the near-forward direction [10]. The volume concentrations with mean diameters of 32 particle size bins (range: 2.5-500 $\mu \mathrm{m}$ ) are determined through inversion of the angular forward-scattering pattern based on Mie theory calculations [23]. By assuming the particles as spherical, the cross-sectional area concentration of particles of each size class was calculated as

$$
\mathrm{AC}_{i}=\frac{3}{2 D_{i}} \mathrm{VC}_{i}
$$

where $\mathrm{AC}_{i}, D_{i}$ and $\mathrm{VC}_{i}$ denote the cross-sectional area concentration, mean diameter and volume concentration of particles in size bin $i$, respectively. As reported in previous studies $[9,24]$, measurements from the LISST instrument usually show significant instability at the smallest and largest size ranges. These instabilities are possibly caused by the presence of particles that are smaller and larger than the measured size range and that of the smallest size ranges might also be associated with stray light [25]. Therefore, the data from the first and the last size bins, which respectively correspond to the smallest and the largest size ranges, were excluded from our analysis. The total cross-sectional area concentration AC was subsequently obtained as

$$
\mathrm{AC}=\sum_{i=2}^{31} \mathrm{AC}_{i}
$$

where $i$ ranges from 2 to 31 with corresponding values of $3.2 \mu \mathrm{m} \leq D_{i} \leq 390 \mu \mathrm{m}$.

Remote sensing reflectance $R_{\mathrm{rs}}(\lambda)$ values were determined using measurements from the Hyper-Profiler II (Satlantic Inc., Halifax, NS, Canada). This instrument includes three inter-calibrated radiometers, i.e., a deck sensor that measures the above-water surface downwelling irradiance $\left(E_{\mathrm{d}}\left(\lambda, 0^{+}\right)\right)$and two underwater sensors that respectively measure the vertical profiles of downwelling irradiance $\left(E_{\mathrm{d}}(\lambda, z)\right)$ and upwelling radiance $\left(L_{\mathrm{u}}(\lambda, z)\right)$. These measured spectra range from 349 to $804 \mathrm{~nm}$ with a mean bandwidth of approximately $3.3 \mathrm{~nm}$. The radiometric measurements were processed to perform calibration, data filtering, binning and interpolation using the manufacturer-provided software Prosoft 7.7.16 [26]. Data with tilt angles $>5^{\circ}$ or $/$ and downward velocity $>0.5 \mathrm{~m} \cdot \mathrm{s}^{-1}$ were excluded during the processing, and $R_{\mathrm{rs}}(\lambda)$ was obtained as 


$$
R_{\mathrm{rs}}(\lambda)=\frac{L_{\mathrm{w}}(\lambda)}{E_{\mathrm{d}}\left(\lambda, 0^{+}\right)}
$$

where $L_{\mathrm{w}}(\lambda)$ is the water-leaving radiance determined from the profile of $L_{\mathrm{u}}(\lambda, z)$ at the upper layer, as described by Rudorff et al. [26].

In this study, we intended to investigate the utility of ocean color measurements for retrieval of AC. Recently, the Geostationary Ocean Color Imager (GOCI), the world's first geostationary ocean color satellite sensor, has become increasingly popular due to its high temporal resolution. GOCI observes the Northeast Asian region 8 times within a day from 8:15 to 15:15 local time (temporal resolution of $1 \mathrm{~h}$ ). In the visible region, GOCI contains 6 bands with central wavelengths of 412, 443, $490,555,660$ and $680 \mathrm{~nm}$. Therefore, in this study, we resampled the in situ hyper-spectral $R_{\mathrm{rs}}(\lambda)$ to the GOCI bands based on the spectral response function.

TSM concentrations were determined gravimetrically by filtration of $0.5-2 \mathrm{~L}$ of seawater onto 47-mm Whatman GF/F glass fiber filters [27]. These filters were pre-weighed on a balance with an accuracy of $0.01 \mathrm{mg}$ and stored in a desiccator before the cruise. Water samples were filtered onto the pre-weighed filters under low vacuum pressure $(<0.01 \mathrm{MPa})$. After filtration, the filters were rinsed three times using $50 \mathrm{~mL}$ MilliQ water to remove immersed salt and immediately frozen at $-20{ }^{\circ} \mathrm{C}$ before drying at $105^{\circ}$ for $4 \mathrm{~h}$ in the laboratory. The filters were reweighed on a balance to obtain the TSM concentrations until the difference between the last two measurements was within $0.02 \mathrm{mg}$. The TSM concentrations were corrected for the sea salt plus water of hydration retention using the method proposed by Stavn et al. [28]. The salinity data used for the correction was from the CTD measurements.

\subsection{Satellite Data}

Level 1B products of top-of-atmosphere radiance of GOCI (with 8 images per day) in 2015 and during our cruise period in 2014 were obtained from the Korea Ocean Satellite Center (KOSC). These products were cropped to the BS and the YS and processed to Level 2 data for $R_{\mathrm{rs}}(\lambda)$ using the GOCI Data Processing Software (GDPS, version 1.3) set to the default parameters and standard atmospheric correction [29]. Subsequently, to derive the monthly variations of AC in the BS and the YS, we produced monthly $R_{\mathrm{rs}}(\lambda)$ in 2015 from the hourly Level $2 R_{\mathrm{rs}}(\lambda)$ using the combined time-series tool of GDPS.

\subsection{Accuracy Assessment}

The performance of the AC estimation model proposed in this study was assessed with comparison between the $R_{\mathrm{rs}}(\lambda)$-retrieved $\mathrm{AC}$ and those measured values [30]. The coefficient of determination $R^{2}$ calculated in the log-log space was used to show how well the derived AC agreed with the measured values. Two other indicators, the root mean squared error (RMSE) and the mean absolute percentage error (MAPE), were also used to demonstrate the scatter between the measured and estimated values, which were calculated as follows [31]:

$$
\begin{gathered}
\text { RMSE }=\sqrt{\frac{1}{N} \sum_{i=1}^{N}\left[y_{\text {est }, i}-y_{\text {mea }, i}\right]^{2}} \\
\text { MAPE }=\frac{1}{N} \sum_{i=1}^{N}\left|\frac{y_{\text {est }, i}-y_{\text {mea }, i} \mid}{y_{\text {mea }, i}}\right| \times 100 \%
\end{gathered}
$$

where $y_{\mathrm{est}, i}$ and $y_{\text {mea, } i}$ represent the estimated and measured AC for the $i$ th sample, respectively, and $N$ is the total number of samples. 


\section{Results}

\subsection{Data Distributions}

The particle concentrations showed wide dynamic ranges and significant variability (Table 1). The TSM varied from 0.53 to $43.88 \mathrm{~g} \cdot \mathrm{m}^{-3}$ with a mean value of $7.60 \mathrm{~g} \cdot \mathrm{m}^{-3}$ (standard variation of $7.25 \mathrm{~g} \cdot \mathrm{m}^{-3}$ ). The variation coefficient of TSM was $95.4 \%$. Compared with TSM, the AC showed more significant variation with a range from 0.12 to $13.00 \mathrm{~m}^{-1}$. The values for the mean, standard variation and variation coefficient of $\mathrm{AC}$ were $1.74 \mathrm{~m}^{-1}, 2.14 \mathrm{~m}^{-1}$ and $123.0 \%$, respectively. In general, the AC was log-normally distributed, as shown in Figure 2.

Correspondingly, the remote sensing reflectance $R_{\mathrm{rs}}(\lambda)$ values of all samples showed large variations in both magnitude and spectral shape, although the spectral shapes generally appeared similar (Table 1 and Figure 3). The spectral variability in magnitude and shape of $R_{\mathrm{rs}}(\lambda)$ were generally in accord with those reported in previous studies in coastal regions [32,33]. For the majority of samples, the $R_{\mathrm{rs}}(\lambda)$ spectra displayed peaks between 550 and $600 \mathrm{~nm}$, whereas the spectral peaks of some samples mainly collected from offshore waters of the Bohai Strait and YS during late summer and autumn were shifted to around $490 \mathrm{~nm}$. The in situ hyper-spectral $R_{\mathrm{rs}}(\lambda)$ were resampled to the GOCI 6 bands according their spectral response functions. The statistics of synthetic GOCI $R_{\mathrm{rs}}(\lambda)$ at 6 bands were summarized in Table 1.

Table 1. Statistics of concentrations of total suspended matters (TSM) and cross-sectional area (AC) and remote sensing reflectance $R_{\mathrm{rs}}(\lambda)$ from all stations.

\begin{tabular}{ccccccc}
\hline Variable & Band $(\mathbf{n m})$ & Min & Max & Mean & S.D. & CV (\%) \\
\hline $\mathrm{TSM}\left(\mathrm{g} \cdot \mathrm{m}^{-3}\right)$ & & 0.53 & 43.88 & 7.60 & 7.25 & 95.4 \\
\hline $\mathrm{AC}\left(\mathrm{m}^{-1}\right)$ & & 0.12 & 13.00 & 1.74 & 2.14 & 123.0 \\
\hline & 412 & 0.0006 & 0.0111 & 0.0042 & 0.0030 & 70.7 \\
& 443 & 0.0008 & 0.0152 & 0.0060 & 0.0045 & 75.2 \\
$R_{\mathrm{rs}}(\lambda)\left(\mathrm{sr}^{-1}\right)$ & 490 & 0.0012 & 0.0217 & 0.0086 & 0.0066 & 76.0 \\
& 555 & 0.0010 & 0.0333 & 0.0110 & 0.0094 & 85.7 \\
& 660 & 0.0001 & 0.0239 & 0.0045 & 0.0057 & 126.1 \\
& 680 & 0.0001 & 0.0220 & 0.0040 & 0.0051 & 127.8 \\
\hline
\end{tabular}

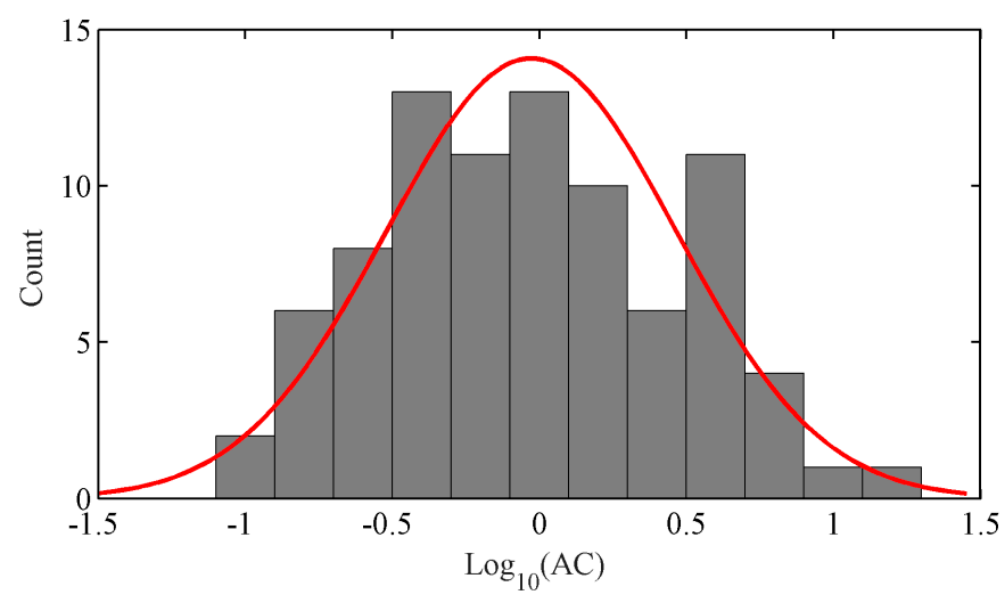

Figure 2. Frequency distribution of cross-sectional area concentration (AC) of particles. The red line represents a log-normally distributed fitting curve. 


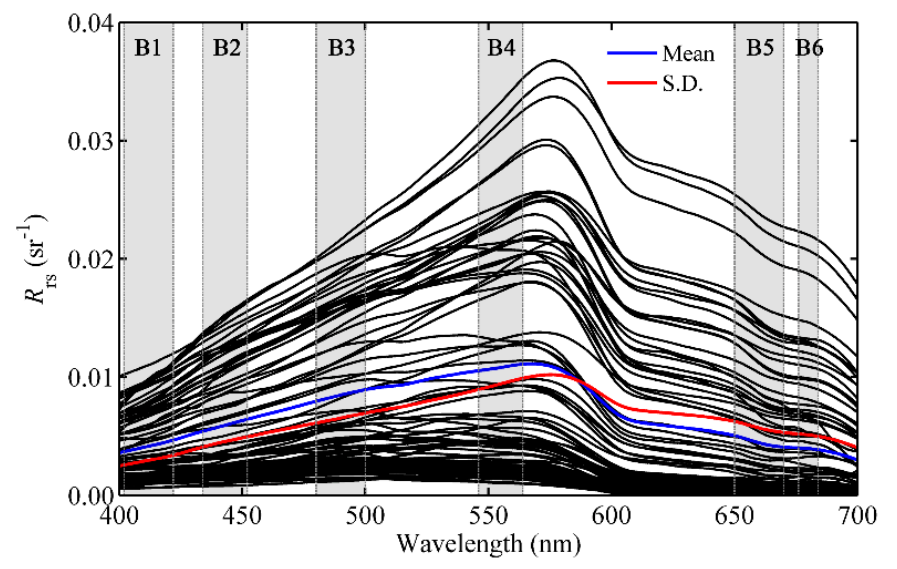

Figure 3. Remote sensing reflectance $R_{\mathrm{rs}}(\lambda)$ from in situ measurements. The values of mean and standard deviation (S.D.) are indicated using blue and red lines, respectively. GOCI 6 channels are indicated using gray bars.

\subsection{Development and Performance of AC Retrieval Model}

Before the model development, we analyzed the relationship between $R_{\mathrm{rs}}(\lambda)$ and $\mathrm{AC}$, and compared with those between $R_{\mathrm{rs}}(\lambda)$ and TSM. Considering the log-normal distribution of AC (Figure 2), the correlations of log-transformed $\mathrm{AC}\left(\log _{10}(\mathrm{AC})\right)$ with $R_{\mathrm{rs}}(\lambda)$ were analyzed for each band of GOCI. The highest correlation between $\log _{10}(\mathrm{AC})$ and $R_{\mathrm{rs}}(\lambda)$ was found at $555 \mathrm{~nm}$ with a value of 0.85 (Figure 4). The second highest correlations occurred at 490 and $660 \mathrm{~nm}$ with values of 0.77 and 0.77 , respectively. We also analyzed the correlation between $\log _{10}(\mathrm{TSM})$ and $R_{\mathrm{rs}}(\lambda)$. Although the variation pattern of the correlations along the wavelength between $\log _{10}(\mathrm{TSM})$ and $R_{\mathrm{rs}}(\lambda)$ was similar to that between $\log _{10}(\mathrm{AC})$ and $R_{\mathrm{rs}}(\lambda)$, the values of the correlations between $\log _{10}(\mathrm{TSM})$ and $R_{\mathrm{rs}}(\lambda)$ were much lower, with the highest correlation of only 0.62 at $555 \mathrm{~nm}$. The causes of these differences are discussed later in Section 4.2.

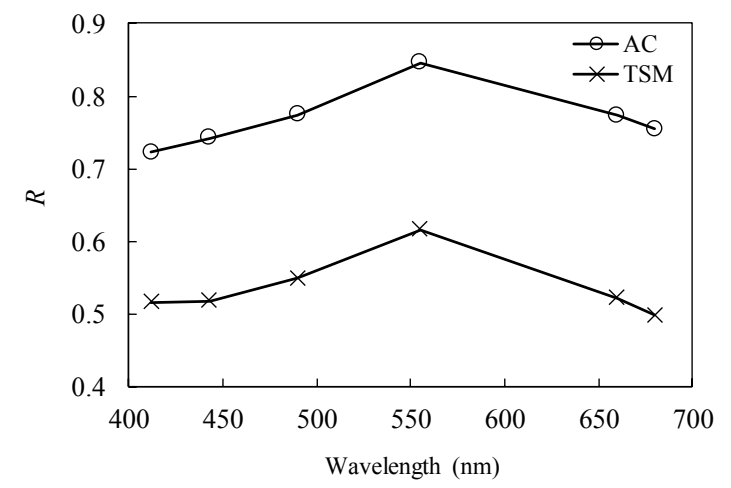

Figure 4. Correlation coefficient $(R)$ of $\log _{10}(\mathrm{AC})$ and $\log _{10}(\mathrm{TSM})$ with remote sensing reflectance $R_{\mathrm{rs}}(\lambda)$ at six bands of GOCI.

Empirical models have been widely used to derive water quality parameters [34,35] because of their simple and easy implementation. Considering the log-normal distribution and the above correlation analysis, we designed an empirical model for retrieval of $\mathrm{AC}$ from $R_{\mathrm{rs}}(\lambda)$, the general form of which can be expressed as

$$
\log _{10}(\mathrm{AC})=k_{1} X^{2}+k_{2} X+k_{0}
$$

where $X$ represents the spectral indicator constructed from $R_{\mathrm{rs}}(\lambda)$, and $k_{0}, k_{1}$, and $k_{2}$ are model parameters that can be derived by regression analysis. This general form of the retrieval model for AC is similar to that used for TSM in previous studies, and single band, band ratios and band arithmetic 
calculations are often used in the spectral indicator $X$ [36-38]. In this study, we designed four forms of $X$ to derive the best model for estimating AC. Regarding the four forms, $X_{1}$ and $X_{2}$ represent the single band and band ratio, respectively; $X_{3}$ denotes the difference of $R_{\mathrm{rs}}(\lambda)$ at two bands; and $X_{4}$ represents the arithmetic calculation of $R_{\mathrm{rs}}(\lambda)$, which was referred from the spectral form used for estimation of TSM [34] (Table 2).

For each spectral indicator $X$, its ability for estimating AC was examined for all possible combinations from GOCI $6 R_{\mathrm{rs}}(\lambda)$ bands. The best band combinations that displayed the highest $R^{2}$ and the lowest RMSE and MAPE for estimation of AC are shown in Table 2. Among the four types of spectral indicator, $X_{3}$ indicating the difference of $R_{\mathrm{rs}}(\lambda)$ between 490 and $555 \mathrm{~nm}$ showed the best performance, and the performance of $X_{1}$ representing the single band of $R_{\mathrm{rs}}(\lambda)$ at $555 \mathrm{~nm}$ was the worst. The $X_{2}$ and $X_{4}$ showed slightly poorer ability than $X_{3}$. Therefore, we recommend $X_{3}$ as the best spectral indicator for estimation of $\mathrm{AC}$ from $R_{\mathrm{rs}}(\lambda)$ and decided to use it in our model. The fitting plots between $\log _{10}(\mathrm{AC})$ and $X_{3}$ are shown in Figure 5. It can be observed that most of the samples cluster around the fitting curve with an $R^{2}$ value of 0.843 . Comparisons between the measured AC and estimated values for the same dataset also showed good agreement with RMSE and MAPE values of $1.145 \mathrm{~m}^{-1}$ and $38.9 \%$, respectively (Table 2 ).

Note that the model fitting of this study was based on the log-transformed AC data, while the fitting can also be conducted directly based on untransformed data. We have compared the two manners for the model fitting, the results indicated that the model based on log-transformed AC data generally performed better than the model based on untransformed data (data not shown), probably because that log-transformation may reduce uncertainty of outliers to some extent. Thus, the log-transformed AC data are recommended to use for model calibration.

Table 2. Summary of the performance of different spectral indicators $X$ for retrieval of the cross-sectional area. $X_{1}$ to $X_{4}$ indicate four forms of $X$.

\begin{tabular}{cccccc}
\hline $\boldsymbol{X}$ & General Form & Best Band (nm) & $\boldsymbol{R}^{\mathbf{2}}$ & RMSE & MAPE (\%) \\
\hline$X_{1}$ & $R_{\mathrm{rs}}\left(\lambda_{1}\right)$ & $\lambda_{1}=555$ & 0.755 & 1.084 & 50.3 \\
$X_{2}$ & $R_{\mathrm{rs}}\left(\lambda_{1}\right) / R_{\mathrm{rs}}\left(\lambda_{2}\right)$ & $\lambda_{1}=660, \lambda_{2}=412$ & 0.807 & 1.095 & 44.2 \\
$X_{3}$ & $R_{\mathrm{rs}}\left(\lambda_{1}\right)-R_{\mathrm{rs}}\left(\lambda_{2}\right)$ & $\lambda_{1}=555, \lambda_{2}=490$ & 0.843 & 1.145 & 38.9 \\
$X_{4}$ & $\frac{R_{\mathrm{rs}}\left(\lambda_{1}\right)+R_{\mathrm{rs}}\left(\lambda_{3}\right)}{\left(R_{\mathrm{rs}}\left(\lambda_{2}\right) / R_{\mathrm{rs}}\left(\lambda_{1}\right)\right)^{1.2}}$ & $\lambda_{1}=555, \lambda_{2}=490, \lambda_{3}=412$ & 0.816 & 1.167 & 44.3 \\
\hline
\end{tabular}

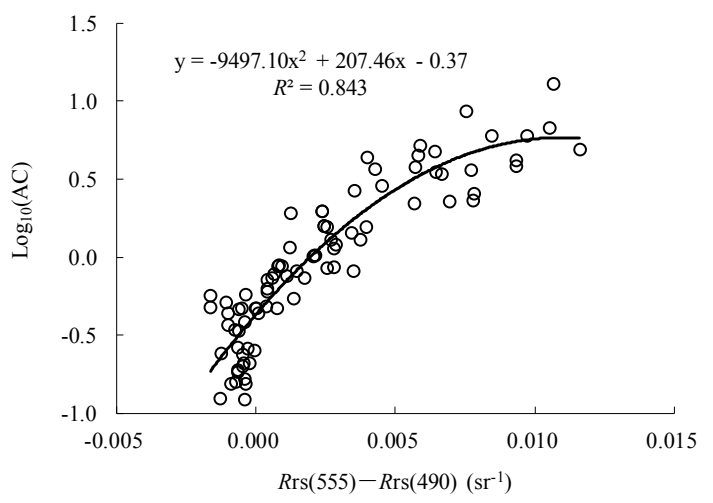

Figure 5. Scatter plots of $\log _{10}(\mathrm{AC})$ versus the difference between $R_{\mathrm{rs}}(555)$ and $R_{\mathrm{rs}}(490)$ of GOCI. Solid black line indicates the fitted curve.

To further evaluate the performance and test the robustness of the AC estimation model, we conducted a cross-validation [39]. In brief, one sample was selected from the full dataset, which was used in model validation. The remaining samples were used in model calibration, and the calibrated model was adapted to derive the AC for the remaining one sample. This procedure was repeated until all of the samples of the full dataset were selected as the validation sample. The estimated AC values 
obtained from the above steps were independent of each other and formed a new validation dataset. Subsequently, comparisons were performed between these estimated AC and the measured values, and $R^{2}$, RMSE and MAPE were calculated. As shown in Figure 6, a strong linear relationship was found between the estimated AC and measured values in logarithmic space, with values of $R^{2}$, RMSE and MAPE of $0.783,1.744 \mathrm{~m}^{-1}$ and $48.4 \%$, respectively.

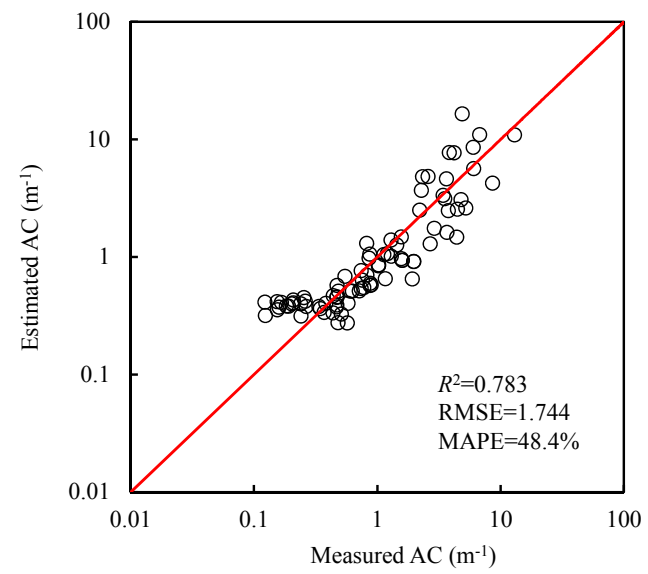

Figure 6. Scatter plots of estimated AC versus measured AC during the cross-validation. The solid red line indicates the 1:1 line.

\subsection{Model Sensitivity Analysis}

The sensitivities of the developed models to the uncertainties in $R_{\mathrm{rs}}(\lambda)$ were examined. We added random errors with a standard deviation of $m$ and average value of 0 to the spectral indicator $X_{3}$ (i.e., the difference of $R_{\mathrm{rs}}(\lambda)$ between 490 or $555 \mathrm{~nm}$ ) of all samples. This process was repeated 1000 times; thus an approximately normal distribution was produced in the added random errors. The mean of the relative errors in the estimated AC compared with those derived from $R_{\mathrm{rs}}(\lambda)$ without addition of errors was subsequently calculated by averaging the errors across the 1000 repetitions. Considering the uncertainty in $X_{3}$ may reach around $40 \%$ for GOCI satellite measurements as shown in Figure 8 later, we varied the standard deviation $m$ of the errors from $5 \%$ to $45 \%$ with an interval of $5 \%$ and conducted the above procedure for each value of $m$.

As shown in Figure 7, it was found that the relative errors in the estimations of AC increased with increases in the random errors added to spectral indicator $X_{3}$, and the increase rate gradually became large. Note that although the relative errors in the estimations of AC gradually became large with the increases of the uncertainty in $X_{3}$, when $45 \%$ random errors were added to $X_{3}$, the relative errors yielded by the model was $20.1 \%$. These results indicate that the AC estimation model is robust for input errors.

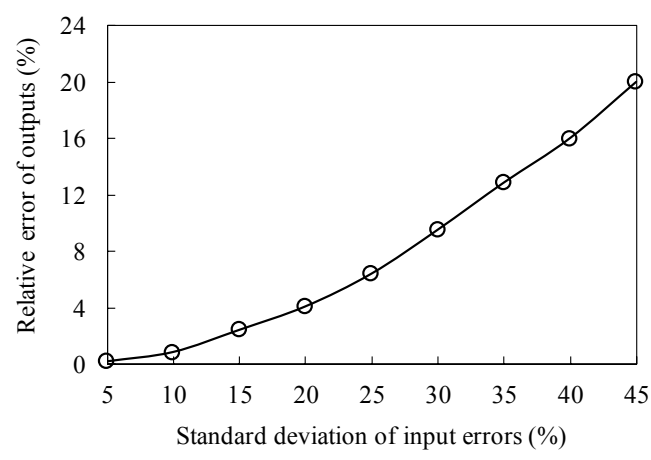

Figure 7. Relative errors in estimation of AC when random errors with standard deviation of $5 \%, 10 \%$, $15 \%, 20 \%, 25 \%, 30 \%, 35 \%, 40 \%$ and $45 \%$ were respectively added to the spectral indicator $X_{3}$. 


\subsection{Model Application to Satellite Data}

We applied the developed AC retrieval model to the GOCI satellite data to preliminarily investigate the spatial and temporal variations of AC in the BS and the YS. Before the application, the satellite derived $R_{\mathrm{rs}}(\lambda)$ and the performance of the AC retrieval model for satellite $R_{\mathrm{rs}}(\lambda)$ was validated based on a dataset containing 28 pairs of in situ measurements and GOCI satellite data. This match-up dataset only included satellite $R_{\mathrm{rs}}(\lambda)$ with an overpass time within $3 \mathrm{~h}$ before and after field measurements $[30,40,41]$. To avoid the influences of outliers, the median $R_{\text {rs }}(\lambda)$ values from a $3 \times 3$ pixel window centered on the locations of the field sampling stations were used as GOCI satellite $R_{\mathrm{rs}}(\lambda)$. In general, satellite derived $R_{\mathrm{rs}}(490)$ and $R_{\mathrm{rs}}(555)$ of the most samples showed good agreement with in situ measured values, while large errors were also observed for some samples (marked by crosses) (Figure 8a,b). However, note that the model of this study uses the spectral indicator $X_{3}$ (i.e., the difference between $R_{\mathrm{rs}}(555)$ and $\left.R_{\mathrm{rs}}(490)\right)$ rather than the single band. We found that although these samples showed large errors in satellite $R_{\mathrm{rs}}(\lambda), X_{3}$ of them were consistent with in situ measured values (Figure $8 \mathrm{c}$ ). Subsequently, these 28 satellite $R_{\mathrm{rs}}(\lambda)$ were used to derive AC by the model which was calibrated based on the remaining subset $(N=58)$ of the full 86 in situ measurements (independent of validation dataset). As shown in Figure 8d, the satellite-derived AC generally agreed well with field measured $\mathrm{AC}$, with values of $R^{2}$, RMSE and MAPE of $0.700,2.126 \mathrm{~m}^{-1}$ and $40.7 \%$, respectively. These results suggest that our model has good performance for satellite application of GOCI data.
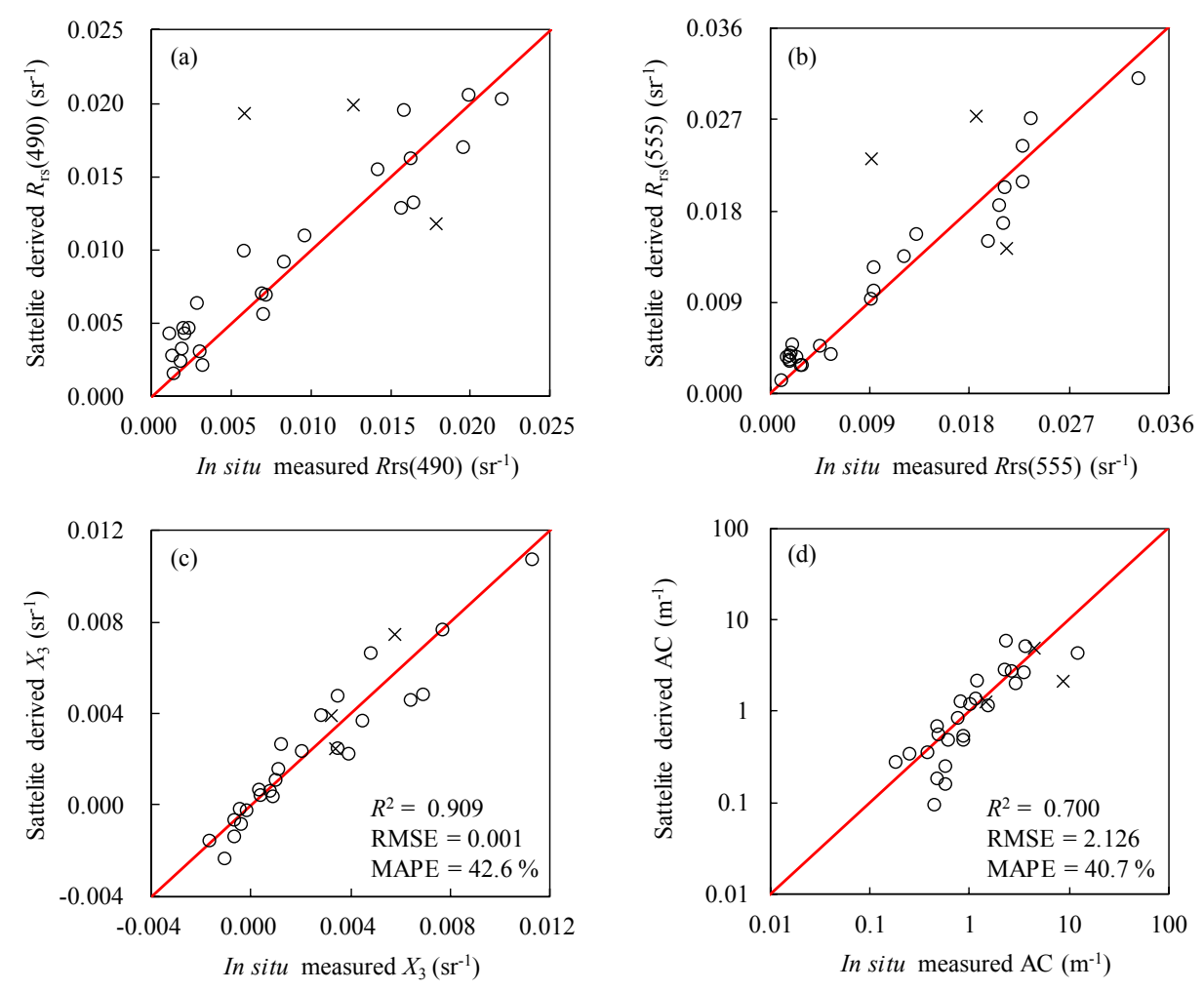

Figure 8. Comparisons of GOCI satellite derived $R_{\mathrm{rs}}(490)$ (a); $R_{\mathrm{rs}}(555)$ (b); spectral indicator $X_{3}$ (i.e., the difference between $R_{\mathrm{rs}}(555)$ and $R_{\mathrm{rs}}(490)$ ) (c) and AC (d) with in situ measured values. The red lines indicate the 1:1 line.

The distributions of the AC estimated from composited GOCI monthly $R_{\mathrm{rs}}(\lambda)$ were shown in Figures 9 and 10. Clear spatial and temporal variations of AC were observed in the BS and the YS (Figure 9). In general, the AC of coastal shallow waters showed much higher values than those in offshore waters, while variations of the AC in coastal regions were lower compared with those in 
offshore waters (Figure 10). The high AC in the Yellow River mouth and the Changiiang River mouth and their adjacent regions might be related to sediment loads from these rivers, and the high AC in other coastal regions is possibly associated with re-suspension of particles driven by tidal mixing and/or wind stress [42,43]. For offshore waters, the AC in the BS is higher than in the YS. At the temporal scale, the AC was the lowest in summer in most regions of the BS and the YS, whereas in winter, the AC showed the highest values, especially in December. During spring and autumn, high values of AC were observed in offshore waters. The lowest and the highest AC during summer and winter might be related to water stratification and strong mixing, respectively, and the high AC in spring and autumn in offshore waters is possibly caused by algae bloom [20,44]. Understanding the controlling factors of the spatial and temporal variability in AC is beyond the scope of this study, but this topic will be further investigated. However, as mentioned above, re-suspension of particles, sediment loads from rivers and water mixing are possible causes. Meanwhile, we note that some coastal regions in images show invalid pixels (white color). These invalid pixels are mainly related to the effects of unsuccessful atmospheric correction. In this study, we used the standard atmospheric correction method to process GOCI data, by which turbid waters are often masked. Atmospheric correction in coastal regions has been a difficult point for ocean color remote sensing for a long time. Further efforts focusing on this issue are still required.

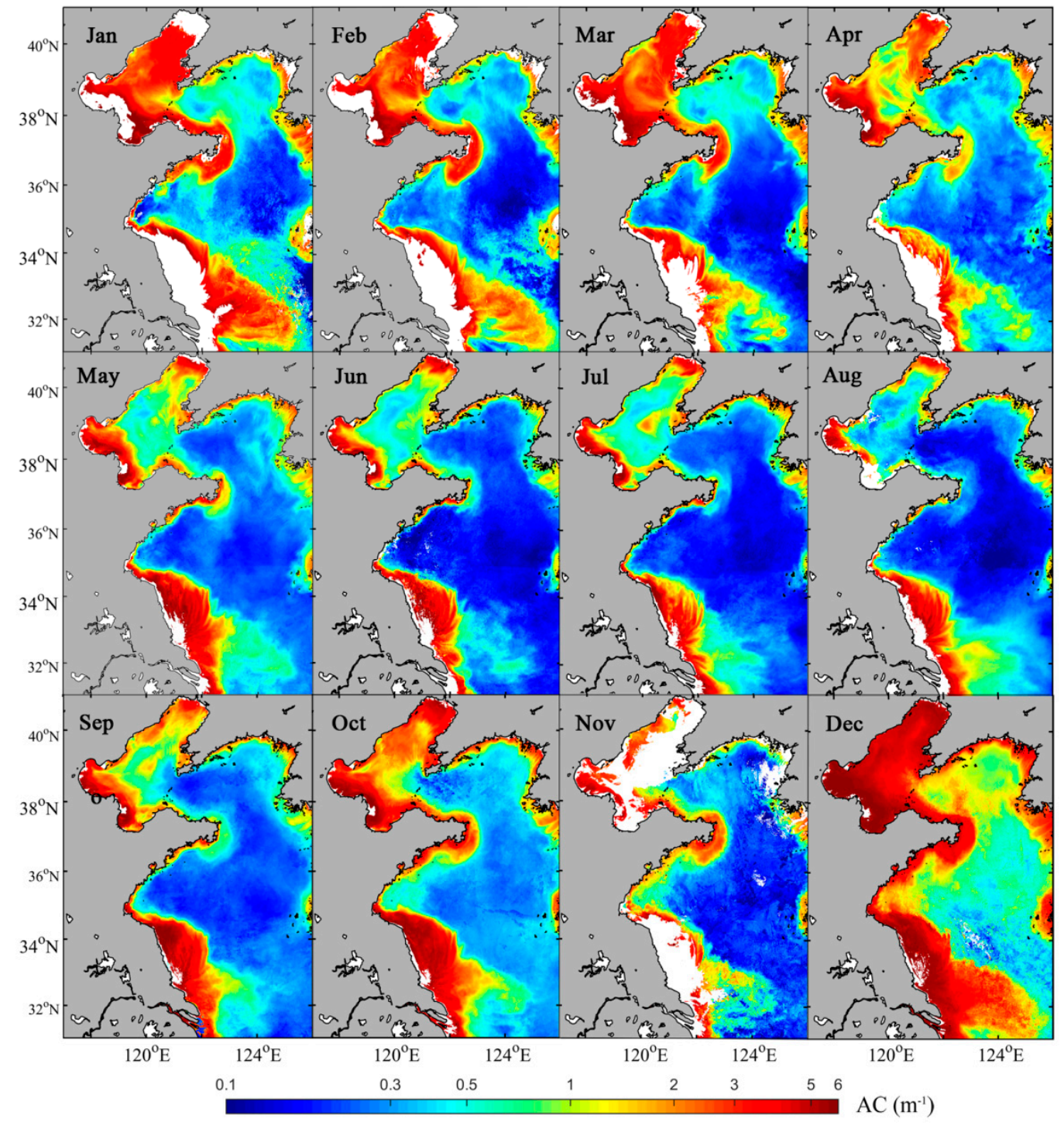

Figure 9. Distributions of the AC derived from GOCI satellite measurements in 2015. 

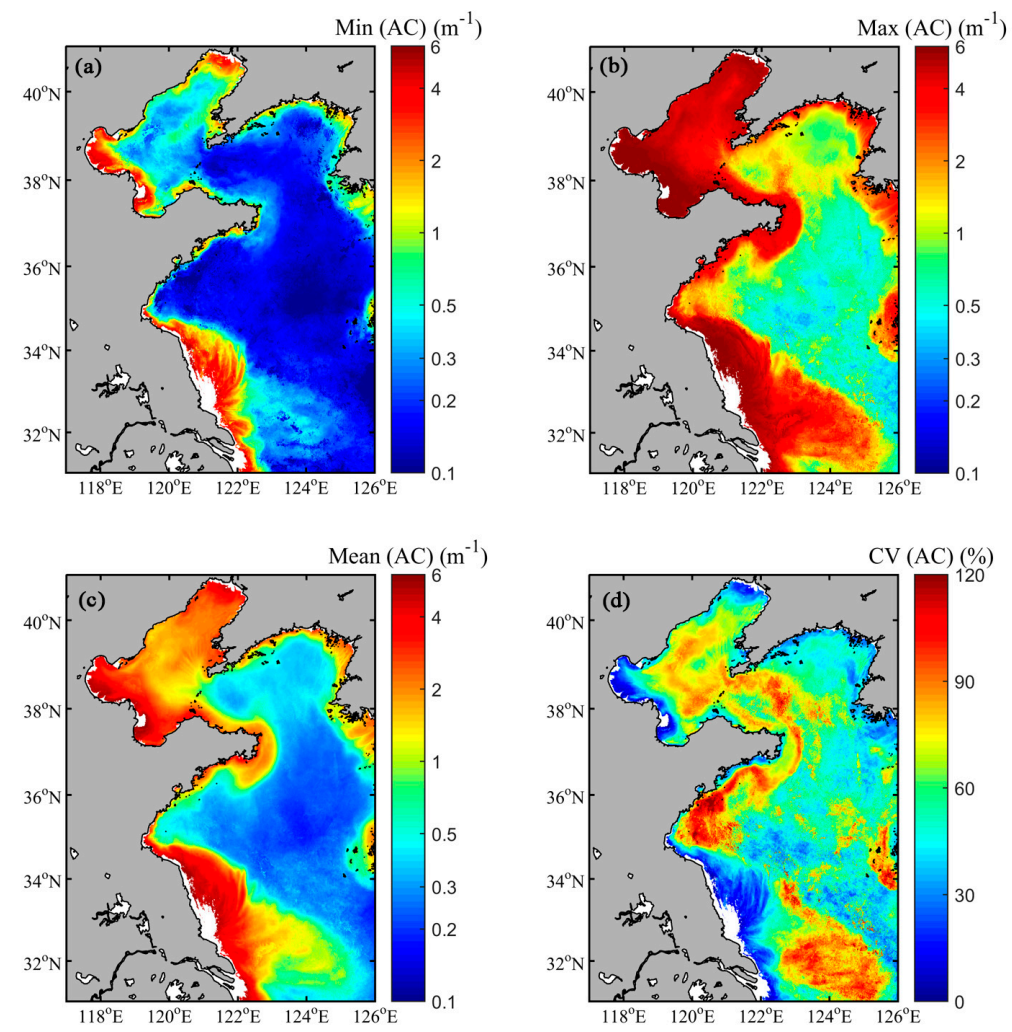

Figure 10. Distributions of the minimum (a); maximum (b); mean (c) and coefficient of variation (d) values of the AC derived from monthly GOCI satellite data in 2015.

\section{Discussion}

\subsection{Rationality and Limitation of AC Retrieval Model}

Suspended matters significantly impact the underwater light field, algae photosynthesis and the ocean color signal through light absorption and scattering processes [3,4]. Theoretical, experimental and in situ studies have proved that the inherent optical properties of suspended particles are more sensitive to AC than TSM $[6,11,12,15]$ because of the direct dependences of the chance of a photon interacting with a particle on cross-sectional area rather than mass [7]. Consequently, remote sensing reflectance $R_{\mathrm{rs}}(\lambda)$ as a function of light absorption and backscattering is also more strongly related to AC than TSM $[7,8,18]$. In this study, as expected, our analysis showed that although the AC varied over a large range, the correlations between $\mathrm{AC}$ and $R_{\mathrm{rs}}(\lambda)$ at six bands of GOCI were strong and were approximately 1.4 times higher than those between $R_{\mathrm{rs}}(\lambda)$ and TSM (Figure 4). The strong relationship between $\mathrm{AC}$ and the inherent optical properties, thus $R_{\mathrm{rs}}(\lambda)$, offers a solid optical basis for deriving AC from $R_{\mathrm{rs}}(\lambda)$.

The retrieval model of AC was empirically determined by comparing the performances of four types of spectral indicators constructed from all possible GOCI satellite band combinations. The difference between $R_{\mathrm{rs}}(\lambda)$ at 490 and $555 \mathrm{~nm}$, which in fact represents the slope of $R_{\mathrm{rs}}(\lambda)$ between these two bands, is recommended as the best spectral indicator for estimation of AC (Table 2 and Figure 5). This observation is consistent with our correlation analysis, which indicated that these two bands showed the highest correlations with the AC (Figure 4). The model sensitivity analysis suggests that our model is robust for uncertainties in $R_{\mathrm{rs}}(\lambda)$ (Figure 7). In general, the AC retrieval model is simple and can be easily implemented in other regions as well as in other ocean color sensors, such as the Sea-viewing Wide Field-of-view Sensor (SeaWiFS), the Moderate Resolution Imaging Spectroradiometer (MODIS) and the Medium Resolution Imaging Spectrometer (MERIS) because bands similar to 490 and $550 \mathrm{~nm}$ are commonly set for most of the ocean color sensors. This was confirmed when we derived a retrieval model of AC for MODIS based on a synthetic dataset of 
MODIS $R_{\mathrm{rs}}(\lambda)$ using the same approach as that for GOCI. We found that for MODIS, the difference between $R_{\mathrm{rs}}(555)$ and $R_{\mathrm{rs}}(488)$ was also the best for deriving the $\mathrm{AC}$, and the model performances were comparable to those of the model for GOCI, with $R^{2}$, RMSE and MAPE values of $0.842,1.146 \mathrm{~m}^{-1}$ and $38.9 \%$, respectively (Figure 11). However, due to the lack of sufficient match-ups of MODIS satellite data and in situ measurements, currently it is difficult to evaluate the performance of the algorithm for real MODIS satellite data.

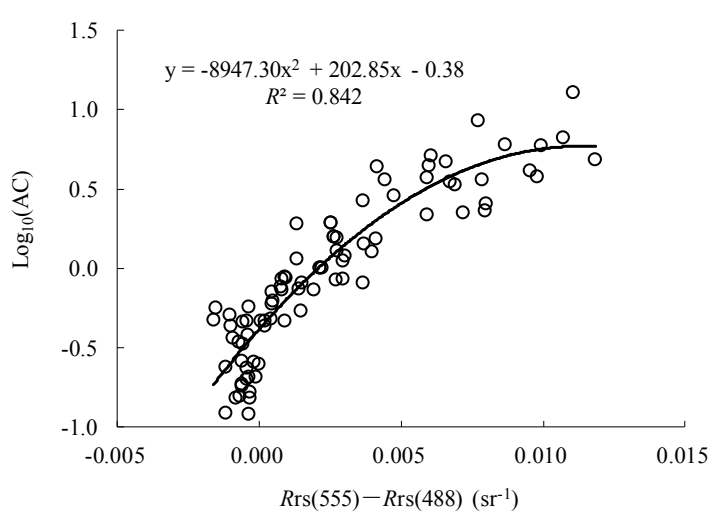

Figure 11. Scatter plots of $\log _{10}(\mathrm{AC})$ versus the difference between $R_{\mathrm{rs}}(555)$ and $R_{\mathrm{rs}}(488)$ of MODIS.

Solid black line indicates the fitted curve.

It was noted that the data used in this study were collected mainly from coastal regions, and a subset even originated from turbid waters, showing mean values of TSM and AC of $7.60 \mathrm{~g} \cdot \mathrm{m}^{-3}$ and $1.74 \mathrm{~m}^{-1}$, respectively, and the highest values reached $43.88 \mathrm{~g} \cdot \mathrm{m}^{-3}$ and $13.00 \mathrm{~m}^{-1}$, respectively (Table 1). These results imply that the model developed in this study might be mostly suitable for coastal regions. We verified this speculation by analyzing the distribution of the percentage errors (PE) in estimations of AC. As shown in Figure 12, when the AC was larger than $0.20 \mathrm{~m}^{-1}$, our model performed well, showing that the PE were uniformly distributed around the two sides of the $0 \%$ line with a mean absolute value of $30.9 \%$. At a notably low AC range $\left(\mathrm{AC}<0.20 \mathrm{~m}^{-1}\right)$, the samples showed significant estimation errors, with $\mathrm{PE}>50 \%$, and the PE values of these samples were positive, indicating overestimations in AC. However, it was noted that the samples were few $(N=11)$. A future hybrid model applicable for both coastal and clear waters, and particularly for clear waters, might further improve the accuracy in estimations of AC, but it is difficult to conduct such an analysis at this stage because of limited samples from clear waters in our dataset. In addition, bio-optical properties of particles in coastal regions are complex and dynamic due to changes in particle assemblages [45]. Although the algorithm of this study performed generally well in the BS and YS, its applicability in additional coastal regions must be validated in further investigations.

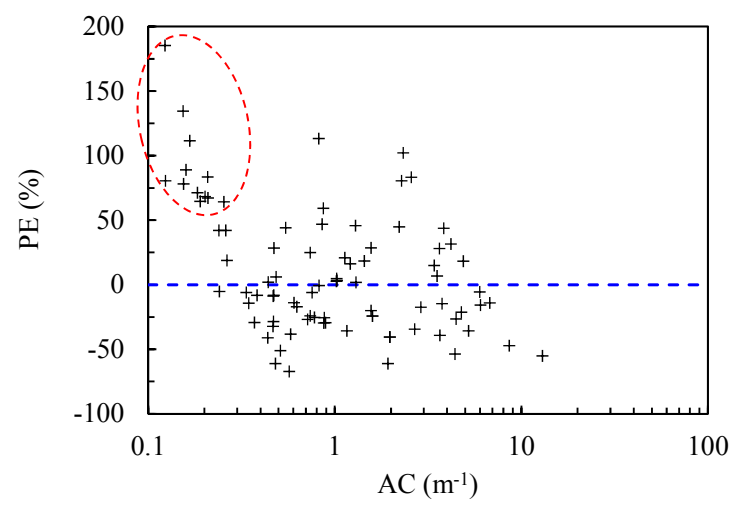

Figure 12. Distributions of percentage error (PE) in estimations of AC using the model developed in this study. Blue dash indicates the PE of $0 \%$. Samples with large PE are circled. 
The AC estimation model proposed in this study uses the difference between $R_{\mathrm{rs}}(550)$ and $R_{\mathrm{rs}}(490)$. It is known that $R_{\mathrm{rs}}(\lambda)$ is regulated by the absorption of pure seawater, particles and colored dissolved organic matter (CDOM), and the backscattering of pure seawater and particles [46]. Usually, absorption and backscattering coefficients of pure seawater are treated as constant values [46]. In this sense, changes in the absorption of CDOM may impact the AC estimation model, since although the absorption of CDOM at 490 and $555 \mathrm{~nm}$ is usually low, it should not be ignored. Due to the lack of in situ measurements of CDOM, we could not exactly examine to what extent CDOM would impact the AC estimation model. The in situ data used in this study collected from large regions covering river-influenced coastal waters and offshore waters, in which CDOM might vary greatly, while the AC model performed generally well. This observation implies that the AC estimation model may be generally robust to CDOM in the BS and YS, while further investigations are required based on available CDOM measurements.

It should be noted that the AC data used in this study were determined from LISST measurements. Due to the inherent limitation of LISST instrument, the AC data only account for information of particles within the size range of 3.2-390 $\mu \mathrm{m}$. Risović [47] showed that sub-micron particles may have significant contribution to backscattering signal, so that the particles measured by LISST may not appropriately explain changes in $b_{\mathrm{bp}}(\lambda)$ and $R_{\mathrm{rs}}(\lambda)$ as well. However, in our previous studies conducted in the BS and YS [15], we found that more than $90 \%$ of variability in $b_{\mathrm{bp}}(\lambda)$ could be explained by the AC of particles measured by LISST. Therefore, although LISST measurements only effectively cover a size range of 3.2-390 $\mu \mathrm{m}$, we believe in our study region, the AC values derived from LISST measurements can effectively explain variations in optical properties. In addition, to describe the relationship between AC and optical properties, particles are usually assumed to be spherical. This assumption is useful and has been widely used in studies of bio-optical properties of particles $[9,13,16,48]$, while we have to admit that this assumption may be not necessarily valid in natural environments, which may bring uncertainty in the relationship between AC and optical properties described in this study. Therefore, regarding the above two issues, more advanced field instruments that can cover larger particle size ranges and reveal more adequate particle shapes should be developed in future that will facilitate development of a more accurate AC estimation model.

\subsection{Implications of Remote Sensing Applications of AC}

The cross-sectional area of suspended particles is a key factor to link the suspended particles with their optical properties. Satellite derived AC using the model proposed in this study provide a new property of suspended particles from space, which may improve our understanding of particle biogeochemical properties and the role of particles in determination of water optical properties. First of all, AC is closely related to the inherent optical properties (i.e., attenuation, scattering and backscattering coefficients) as shown in Equation (1) for the backscattering coefficient as an example, and the relationships are often observed to be strong [11,12,15]. This observation indicates that the inherent optical properties can be modeled from AC with knowledge of the corresponding efficiency factors. Additionally, because the chances of photons interacting with particles directly depend on the cross-sectional area, the light conditions underwater might also be estimated based on the information about AC. In our dataset, strong correlation between AC and transparency $\left(R^{2}=0.87\right)$ in log-log space was observed, implying that AC retrieved from satellite observations using our model might have great potential for mapping transparency and photosynthetically active radiation, which is important for phytoplankton photosynthesis.

Inherent optical properties are linked with AC by efficiency factors. Many field investigations have observed clear differences in attenuation and backscattering efficiencies among different particle compositions (e.g., phytoplankton and mineral particles) [9,15,48-51]. For instance, Vaillancourt et al. [50] showed that $Q_{\text {bbe }}(\lambda)$ levels at $620 \mathrm{~nm}$ for cultured 28 phytoplankton species varied from 0.001 to 0.068 with a mean of 0.011 ; and Peng and Effler [51] found that $Q_{\text {bbe }}(\lambda)$ levels at $650 \mathrm{~nm}$ of mineral particles ranged from 0.046 to 0.062 with a median value of 0.051 . Particularly, 
Bowers et al. [48] observed a strong positive relationship between $Q_{\text {bbe }}(665)$ and particle composition (the ratio of minerals to total suspended matters) $\left(R^{2}=0.62\right)$, implying that $Q_{\mathrm{bbe}}(665)$ might be used to detect particle composition. Similarly, in the BS and the YS, Wang et al. [15] found that $Q_{\text {bbe }}(640)$ clearly classified particles into two types respectively dominated by organic or relatively large particles and small mineral particles. As shown in this study, AC can be successfully derived from satellite measurements using the model developed in this work. At the same time, values of $b_{\mathrm{bp}}(\lambda)$ can also be retrieved from satellite $R_{\mathrm{rs}}(\lambda)$ using an inherent optical properties algorithm [52,53]. Consequently, $Q_{\mathrm{bbe}}(\lambda)$ can be easily calculated as the ratio of $b_{\mathrm{bp}}(\lambda)$ to AC. When satellite $Q_{\mathrm{bbe}}(\lambda)$ data become available, particle composition or particle classification might be mapped based on the findings of previous studies [15,48], and specific studies focusing on this topic are expected in future.

Although TSM has been widely used to quantify the amount of particles, and various remote sensing algorithms have been developed to map TSM from satellite measurements [27,54-57], the correlation of the inherent optical properties with TSM is weaker compared with AC. This may cause an unstable relationship between TSM and $R_{\mathrm{rs}}(\lambda)$, and thereby bring large errors in TSM estimations which could reach a factor of 10 if their values are derived from satellite measurements $[8,18,58]$. The reason for the large uncertainties is attributed to the fact that $R_{\mathrm{rs}}(\lambda)$ reflects the information not only for TSM but also for particle size distribution and density which might also vary by up to several orders of magnitude from location to location due to changes in particle composition and flocculation [13,59]. However, because of a more direct relationship between AC and $R_{\mathrm{rs}}(\lambda)$, retrieval of $\mathrm{AC}$ from $R_{\mathrm{rs}}(\lambda)$ suffers fewer influences from changes in particle size distribution and density. The relationship between TSM and AC can be approximately expressed as $[7,9]$.

$$
\mathrm{TSM}=\frac{2 \mathrm{AC}}{3 \rho_{\mathrm{a}} D_{\mathrm{A}}}
$$

This implies that satellite derived AC might offer an alternative approach for mapping of TSM. However, at this stage, it is important to note that estimation of TSM from AC also requires additional information on particle size and density, which is beyond of the scope of this study. Meanwhile, it is still needed to further evaluate whether this approach can improve the estimation of TSM.

\section{Conclusions}

The cross-sectional area of suspended particles is of fundamental importance for understanding water optical properties. Based on in situ measurements conducted in the Bohai Sea (BS) and the Yellow Sea (YS), this study proposed an algorithm for deriving concentration of particle cross-sectional area (AC) from GOCI satellite measurements. The designed algorithm uses the slope of the remote sensing reflectance $R_{\mathrm{rs}}(\lambda)$ between 490 and $555 \mathrm{~nm}$ as an input. Both in situ and satellite validations indicated that the algorithm shows good performances, with the $R^{2}$ values of 0.783 and 0.700 , RMSE values of 1.744 and $2.126 \mathrm{~m}^{-1}$ and MAPE values of $48.3 \%$ and $40.7 \%$, respectively. This result indicates the great potential of the algorithm for mapping of AC from satellite measurements, which was confirmed by the generally reasonable patterns of the temporal and spatial distributions of AC derived using the new algorithm in the BS and the YS. Overall, this study provides a technological basis for estimation of AC from satellite measurements in the BS and the YS, and it may be easily implemented in other regions and for other ocean color sensors, while further investigations are required. The values of $A C$ derived from satellite measurements might offer new potential applications of ocean color, such as modeling of the inherent optical properties of particulates, deriving water transparency, estimating particle composition and possibly improvement in the concentration estimations of total suspended particles, topics that will be specifically studied in future work.

Acknowledgments: Special thanks to Shuguo Chen and other members of the group led by Tinglu Zhang in Ocean University of China, other members of the group led by Zhongfeng Qiu in Nanjing University of Information Science \& Technology and the captains, officers, and crews of R/V Dongfanghong 2 for their significant contributions on field sampling and measurements. We also would like to thank the anonymous reviewers for 
their constructive comments towards improving this manuscript. This work is jointly supported by the National Natural Science Foundation of China (NSFC) (41506200, 41276186, 41576172), the Natural Science Foundation of Jiangsu Province (BK20150914, BK20151526), the National Key Research and Development Program of China (2016YFC1400901, 2016YFC1400904), the Natural Science Foundation of the Jiangsu Higher Education Institutions of China (15KJB170015), the Priority Academic Program Development of Jiangsu Higher Education Institutions (PAPD), the Public Science and Technology Research Funds Projects of Ocean (201005030), the Startup Foundation for Introducing Talent of NUIST (2015r007), the National Programme on Global Change and Air-sea Interaction (GASI-03-03-01-01), the Priority Academic Program Development of Jiangsu Higher Education Institutions (PAPD), the Public Science and Technology Research Funds Projects of Ocean (201005030), and sponsored by Qing Lan Project.

Author Contributions: Shengqiang Wang designed this study and the algorithm; Yu Huan contributed to the data analyses and drafted the manuscript; Zhongfeng Qiu, Deyong Sun and Hailong Zhang assisted with developing the research design and results interpretation; Lufei Zheng and Cong Xiao contributed to the interpretation of results and manuscript revision.

Conflicts of Interest: The authors declare no conflict of interest.

\section{References}

1. Doxaran, D.; Froidefond, J.-M.; Castaing, P.; Babin, M. Dynamics of the turbidity maximum zone in a macrotidal estuary (the Gironde, France): Observations from field and MODIS satellite data. Estuar. Coast. Shelf Sci. 2009, 81, 321-332. [CrossRef]

2. Anderson, R.F.; Hayes, C.T. Characterizing marine particles and their impact on biogeochemical cycles in the geotraces program. Prog. Oceanogr. 2015, 133, 1-5. [CrossRef]

3. Morel, A. Optics of marine particles and marine optics. In Particle Analysis in Oceanography; Demers, S., Ed.; Springer: Berlin, Germany, 1991; pp. 141-188.

4. Babin, M.; Morel, A.; Fournier-Sicre, V.; Fell, F.; Stramski, D. Light scattering properties of marine particles in coastal and open ocean waters as related to the particle mass concentration. Limnol. Oceanogr. 2003, 48, 843-859. [CrossRef]

5. Gordon, H.R.; Morel, A.Y. Remote Assessment of Ocean Color for Interpretation of Satellite Visible Imagery: A Review; Springer: Berlin, Germany, 1983; Volume 4.

6. Mobley, C.D. Light and Water: Radiative Transfer in Natural Waters; Academic Press: Cambridge, MA, USA, 1994.

7. Bowers, D.; Braithwaite, K. Evidence that satellites sense the cross-sectional area of suspended particles in shelf seas and estuaries better than their mass. Geo-Mar. Lett. 2012, 32, 165-171. [CrossRef]

8. Mikkelsen, O.A. Variation in the projected surface area of suspended particles: Implications for remote sensing assessment of TSM. Remote Sens. Environ. 2002, 79, 23-29. [CrossRef]

9. Neukermans, G.; Loisel, H.; Mériaux, X.; Astoreca, R.; McKee, D. In situ variability of mass-specific beam attenuation and backscattering of marine particles with respect to particle size, density, and composition. Limnol. Oceanogr. 2012, 57, 124-144. [CrossRef]

10. Agrawal, Y.; Pottsmith, H. Instruments for particle size and settling velocity observations in sediment transport. Mar. Geol. 2000, 168, 89-114. [CrossRef]

11. Hatcher, A.; Hill, P.; Grant, J. Optical backscatter of marine flocs. J. Sea Res. 2001, 46, 1-12. [CrossRef]

12. Flory, E.; Hill, P.; Milligan, T.; Grant, J. The relationship between floc area and backscatter during a spring phytoplankton bloom. Deep Sea Res. Part I Oceanogr. Res. Pap. 2004, 51, 213-223. [CrossRef]

13. Boss, E.; Slade, W.; Hill, P. Effect of particulate aggregation in aquatic environments on the beam attenuation and its utility as a proxy for particulate mass. Opt. Express 2009, 17, 9408-9420. [CrossRef] [PubMed]

14. Bowers, D.; Braithwaite, K.; Nimmo-Smith, W.; Graham, G. The optical efficiency of flocs in shelf seas and estuaries. Estuar. Coast. Shelf Sci. 2011, 91, 341-350. [CrossRef]

15. Wang, S.; Qiu, Z.; Sun, D.; Shen, X.; Zhang, H. Light beam attenuation and backscattering properties of particles in the Bohai Sea and Yellow Sea with relation to biogeochemical properties. J. Geophys. Res. Oceans 2016, 121, 3955-3969. [CrossRef]

16. Bowers, D.; Braithwaite, K.; Nimmo-Smith, W.; Graham, G. Light scattering by particles suspended in the sea: The role of particle size and density. Cont. Shelf Res. 2009, 29, 1748-1755. [CrossRef]

17. Kostadinov, T.S.; Siegel, D.A.; Maritorena, S. Retrieval of the particle size distribution from satellite ocean color observations. J. Geophys. Res. 2009, 114, C09015. [CrossRef] 
18. Bale, A.; Tocher, M.; Weaver, R.; Hudson, S.; Aiken, J. Laboratory measurements of the spectral properties of estuarine suspended particles. Neth. J. Aquat. Ecol. 1994, 28, 237-244. [CrossRef]

19. Wei, H.; Sun, J.; Moll, A.; Zhao, L. Phytoplankton dynamics in the Bohai Sea-Observations and modelling. J. Mar. Syst. 2004, 44, 233-251. [CrossRef]

20. Chen, C.-T.A. Chemical and physical fronts in the Bohai, Yellow and East China Seas. J. Mar. Syst. 2009, 78, 394-410. [CrossRef]

21. Zhang, M.; Tang, J.; Song, Q.; Dong, Q. Backscattering ratio variation and its implications for studying particle composition: A case study in Yellow and East China Seas. J. Geophys. Res. Oceans 2010, 115. [CrossRef]

22. Qiu, Z.; Wu, T.; Su, Y. Retrieval of diffuse attenuation coefficient in the china seas from surface reflectance. Opt. Express 2013, 21, 15287-15297. [CrossRef] [PubMed]

23. Agrawal, Y.; Whitmire, A.; Mikkelsen, O.A.; Pottsmith, H. Light scattering by random shaped particles and consequences on measuring suspended sediments by laser diffraction. J. Geophys. Res. Oceans 2008, 113. [CrossRef]

24. Traykovski, P.; Latter, R.J.; Irish, J.D. A laboratory evaluation of the laser in situ scattering and transmissometery instrument using natural sediments. Mar. Geol. 1999, 159, 355-367. [CrossRef]

25. Reynolds, R.; Stramski, D.; Wright, V.; Woźniak, S. Measurements and characterization of particle size distributions in coastal waters. J. Geophys. Res. Oceans 2010, 115. [CrossRef]

26. De Moraes Rudorff, N.; Frouin, R.; Kampel, M.; Goyens, C.; Meriaux, X.; Schieber, B.; Mitchell, B.G. Ocean-color radiometry across the southern atlantic and southeastern pacific: Accuracy and remote sensing implications. Remote Sens. Environ. 2014, 149, 13-32. [CrossRef]

27. Miller, R.L.; McKee, B.A. Using MODIS Terra $250 \mathrm{~m}$ imagery to map concentrations of total suspended matter in coastal waters. Remote Sens. Environ. 2004, 93, 259-266. [CrossRef]

28. Stavn, R.H.; Rick, H.J.; Falster, A.V. Correcting the errors from variable sea salt retention and water of hydration in loss on ignition analysis: Implications for studies of estuarine and coastal waters. Estuar. Coast. Shelf Sci. 2009, 81, 575-582. [CrossRef]

29. Wang, M.; Gordon, H.R. A simple, moderately accurate, atmospheric correction algorithm for SeaWiFS. Remote Sens. Environ. 1994, 50, 231-239. [CrossRef]

30. Hyde, K.J.; O'Reilly, J.E.; Oviatt, C.A. Validation of SeaWiFS chlorophyll a in Massachusetts Bay. Cont. Shelf Res. 2007, 27, 1677-1691. [CrossRef]

31. Antoine, D.; d'Ortenzio, F.; Hooker, S.B.; Bécu, G.; Gentili, B.; Tailliez, D.; Scott, A.J. Assessment of uncertainty in the ocean reflectance determined by three satellite ocean color sensors (MERIS, SeaWiFS and MODIS-A) at an offshore site in the mediterranean sea (BOUSSOLE project). J. Geophys. Res. Oceans 2008, 113. [CrossRef]

32. He, X.; Bai, Y.; Pan, D.; Huang, N.; Dong, X.; Chen, J.; Chen, C.-T.A.; Cui, Q. Using geostationary satellite ocean color data to map the diurnal dynamics of suspended particulate matter in coastal waters. Remote Sens. Environ. 2013, 133, 225-239. [CrossRef]

33. Sun, D.; Hu, C.; Qiu, Z.; Cannizzaro, J.P.; Barnes, B.B. Influence of a red band-based water classification approach on chlorophyll algorithms for optically complex estuaries. Remote Sens. Environ. 2014, 155, 289-302. [CrossRef]

34. Tassan, S. Local algorithms using seawifs data for the retrieval of phytoplankton, pigments, suspended sediment, and yellow substance in coastal waters. Appl. Opt. 1994, 33, 2369-2378. [CrossRef] [PubMed]

35. O’Reilly, J.E.; Maritorena, S.; Mitchell, B.G.; Siegel, D.A.; Carder, K.L.; Garver, S.A.; Kahru, M.; McClain, C. Ocean color chlorophyll algorithms for SeaWiFS. J. Geophys. Res. Oceans 1998, 103, 24937-24953. [CrossRef]

36. Doxaran, D.; Froidefond, J.-M.; Lavender, S.; Castaing, P. Spectral signature of highly turbid waters: Application with SPOT data to quantify suspended particulate matter concentrations. Remote Sens. Environ. 2002, 81, 149-161. [CrossRef]

37. Mao, Z.; Chen, J.; Pan, D.; Tao, B.; Zhu, Q. A regional remote sensing algorithm for total suspended matter in the East China Sea. Remote Sens. Environ. 2012, 124, 819-831. [CrossRef]

38. Siswanto, E.; Tang, J.; Yamaguchi, H.; Ahn, Y.-H.; Ishizaka, J.; Yoo, S.; Kim, S.-W.; Kiyomoto, Y.; Yamada, K.; Chiang, C. Empirical ocean-color algorithms to retrieve chlorophyll-a, total suspended matter, and colored dissolved organic matter absorption coefficient in the Yellow and East China Seas. J. Oceanogr. 2011, 67, 627-650. [CrossRef] 
39. Kohavi, R. A study of cross-validation and bootstrap for accuracy estimation and model selection. In Proceedings of the 14th International Joint Conference on Artificial Intelligence, Montreal, QC, Canada, 20-25 August 1995; Volume 14, pp. 1137-1145.

40. Bailey, S.W.; Werdell, P.J. A multi-sensor approach for the on-orbit validation of ocean color satellite data products. Remote Sens. Environ. 2006, 102, 12-23. [CrossRef]

41. Cui, T.; Zhang, J.; Groom, S.; Sun, L.; Smyth, T.; Sathyendranath, S. Validation of MERIS ocean-color products in the Bohai Sea: A case study for turbid coastal waters. Remote Sens. Environ. 2010, 114, 2326-2336. [CrossRef]

42. Yang, S.Y.; Jung, H.S.; Lim, D.I.; Li, C.X. A review on the provenance discrimination of sediments in the Yellow Sea. Earth-Sci. Rev. 2003, 63, 93-120. [CrossRef]

43. Jiang, W.; Pohlmann, T.; Sun, J.; Starke, A. SPM transport in the Bohai Sea: Field experiments and numerical modelling. J. Mar. Syst. 2004, 44, 175-188. [CrossRef]

44. Xu, Y.; Ishizaka, J.; Yamaguchi, H.; Siswanto, E.; Wang, S. Relationships of interannual variability in SST and phytoplankton blooms with giant jellyfish (Nemopilema nomurai) outbreaks in the Yellow Sea and East China Sea. J. Oceanogr. 2013, 69, 511-526. [CrossRef]

45. Braithwaite, K.; Bowers, D.; Smith, W.N.; Graham, G.; Agrawal, Y.; Mikkelsen, O. Observations of particle density and scattering in the Tamar Estuary. Mar. Geol. 2010, 277, 1-10. [CrossRef]

46. Gordon, H.R.; Brown, O.B.; Evans, R.H.; Brown, J.W.; Smith, R.C.; Baker, K.S.; Clark, D.K. A semianalytic radiance model of ocean color. J. Geophys. Res. Atmos. 1988, 93, 10909-10924. [CrossRef]

47. Risović, D. Effect of suspended particulate-size distribution on the backscattering ratio in the remote sensing of seawater. Appl. Opt. 2002, 41, 7092-7101. [CrossRef] [PubMed]

48. Bowers, D.; Hill, P.; Braithwaite, K. The effect of particulate organic content on the remote sensing of marine suspended sediments. Remote Sens. Environ. 2014, 144, 172-178. [CrossRef]

49. Ahn, Y.-H.; Bricaud, A.; Morel, A. Light backscattering efficiency and related properties of some phytoplankters. Deep Sea Res. Part I Oceanogr. Res. Pap. 1992, 39, 1835-1855. [CrossRef]

50. Vaillancourt, R.D.; Brown, C.W.; Guillard, R.R.; Balch, W.M. Light backscattering properties of marine phytoplankton: Relationships to cell size, chemical composition and taxonomy. J. Plankton Res. 2004, 26, 191-212. [CrossRef]

51. Peng, F.; Effler, S.W. Characterizations of individual suspended mineral particles in Western Lake Erie: Implications for light scattering and water clarity. J. Gt. Lakes Res. 2010, 36, 686-698. [CrossRef]

52. Lee, Z.; Carder, K.L.; Arnone, R.A. Deriving inherent optical properties from water color: A multiband quasi-analytical algorithm for optically deep waters. Appl. Opt. 2002, 41, 5755-5772. [CrossRef] [PubMed]

53. Smyth, T.J.; Moore, G.F.; Hirata, T.; Aiken, J. Semianalytical model for the derivation of ocean color inherent optical properties: Description, implementation, and performance assessment. Appl. Opt. 2006, 45, 8116-8131. [CrossRef] [PubMed]

54. Binding, C.; Bowers, D.; Mitchelson-Jacob, E. Estimating suspended sediment concentrations from ocean colour measurements in moderately turbid waters; the impact of variable particle scattering properties. Remote Sens. Environ. 2005, 94, 373-383. [CrossRef]

55. Qiu, Z. A simple optical model to estimate suspended particulate matter in Yellow River Estuary. Opt. Express 2013, 21, 27891-27904. [CrossRef] [PubMed]

56. Chen, J.; Cui, T.; Qiu, Z.; Lin, C. A three-band semi-analytical model for deriving total suspended sediment concentration from HJ-1A/CCD data in turbid coastal waters. ISPRS J. Photogramm. 2014, 93, 1-13. [CrossRef]

57. Kong, J.-L.; Sun, X.-M.; Wong, D.W.; Chen, Y.; Yang, J.; Yan, Y.; Wang, L.-X. A semi-analytical model for remote sensing retrieval of suspended sediment concentration in the gulf of Bohai, China. Remote Sens. 2015, 7, 5373-5397. [CrossRef]

58. Baker, E.T.; Lavelle, J.W. The effect of particle size on the light attenuation coefficient of natural suspensions. J. Geophys. Res. 1984, 89, 8197-8203. [CrossRef]

59. Mikkelsen, O.; Pejrup, M. In situ particle size spectra and density of particle aggregates in a dredging plume. Mar. Geol. 2000, 170, 443-459. [CrossRef]

(C) 2016 by the authors; licensee MDPI, Basel, Switzerland. This article is an open access article distributed under the terms and conditions of the Creative Commons Attribution (CC-BY) license (http://creativecommons.org/licenses/by/4.0/). 